
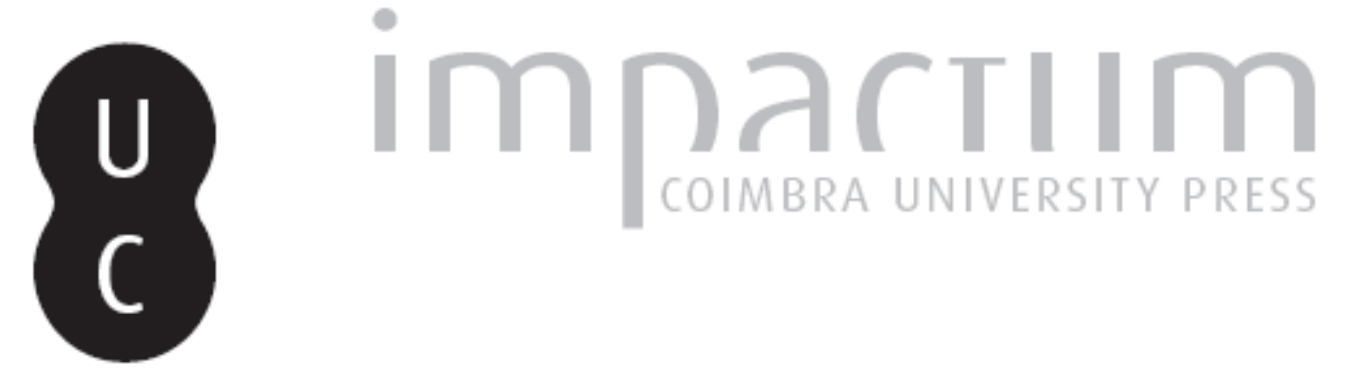

\title{
O sítio romano-árabe da Lezíria: 1. a terra sigillata itálica e sudgálica
}

Autor(es): $\quad$ Arruda, Ana Margarida; Dias, Ana Carvalho

Publicado por: Imprensa da Universidade de Coimbra

URL persistente:

URI:http://hdl.handle.net/10316.2/45657

DOI:

DOI:https://dx.doi.org/10.14195/1647-8657_24_5

Accessed : $\quad$ 26-Apr-2023 13:04:52

A navegação consulta e descarregamento dos títulos inseridos nas Bibliotecas Digitais UC Digitalis, UC Pombalina e UC Impactum, pressupõem a aceitação plena e sem reservas dos Termos e Condições de Uso destas Bibliotecas Digitais, disponíveis em https://digitalis.uc.pt/pt-pt/termos.

Conforme exposto nos referidos Termos e Condições de Uso, o descarregamento de títulos de acesso restrito requer uma licença válida de autorização devendo o utilizador aceder ao(s) documento(s) a partir de um endereço de IP da instituição detentora da supramencionada licença.

Ao utilizador é apenas permitido o descarregamento para uso pessoal, pelo que o emprego do(s) título(s) descarregado(s) para outro fim, designadamente comercial, carece de autorização do respetivo autor ou editor da obra.

Na medida em que todas as obras da UC Digitalis se encontram protegidas pelo Código do Direito de Autor e Direitos Conexos e demais legislação aplicável, toda a cópia, parcial ou total, deste documento, nos casos em que é legalmente admitida, deverá conter ou fazer-se acompanhar por este aviso.

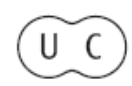


FACULDADE DE LETRAS

INSTITUTO DE ARQUEOLOGIA

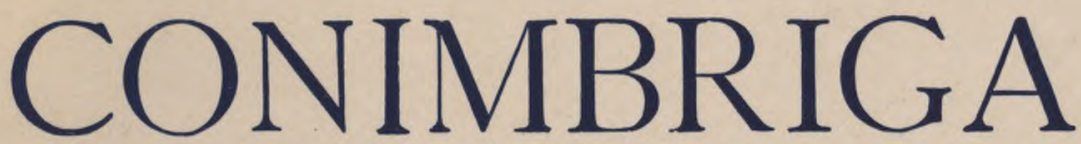

VOLUMEXXIV

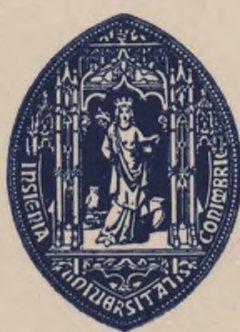

UNIVERSIDADE DE COIMBRA

1985 
Ana Margarida Arruda

Ana Carvalho Dias

Investigadores da Unidade de Arqueologia do Centro de História da Universidade de Lisboa

O SÍTIO ROMANO-ÁRABE DA LEZÍRIA: 1. A TERRA SIGILLATA

ITÁLICA E SUDGÁLICA

«Conimbriga», XXIV (1985), p. 111-124

Resumo: OS autores dâo a conhecer um sítio arqueológico inédito em Castro Marim, identificado em 1982 pela equipa da Unidade de Arqueologia do Centro de História e no qual se recolheu um considerável conjunto de cerâmicas romanas e árabes. Dele se publicam agora vinte e três fragmentos de terra sigillata itálica e sudgálica. A sua proximidade com um sítio chave actualmente em escavação por um dos signatários (A.M.A.), o Castelo de Castro Marim, reveste a Lezíria de um interesse particular, ao que não é estranho o significado da foz do Guadiana, como área portuária e de entrada de influências exteriores.

RÉSUMÉ: Un site archéologique inconnu, localisé à Castro Marim, a été identifié en 1982 par l'équipe de l'Unité d'Archéologie du Centre d'Histoire de l'Université de Lisbonne. Le site a délivré une grande quantité de céramiques romaines dont on publie vingt-trois fragments de céramique sigillée italique et sud-galique. Sa proximité d'un site clef, actuelement en cours de fouilles - le Chateau de Castro Marim - donne à Lezíria un intérêt particulier. Il faut aussi souligner sa position sur les bouches du Guadiana, un fleuve qui a joué un rôle important dans l'évolution du peuplement du sud du Portugal. 
(Página deixada propositadamente em branco) 


\section{O SÍTIO ROMANO-ÁRABE DA LEZÍRIA: 1. A TERRA SIGILLATA ITÁLICA E SUDGÁLICA}

\section{Introdução}

No Verão de 1982, uma equipa da Unidade de Arqueologia do Centro de Historia da Universidade de Lisboa levou a efeito prospecções arqueológicas nos concelhos de Vila Real de Santo Antonio, Castro Marim e Alcoutim, numa vasta área abrangida pelas C. M. P. 591 e 600. Dezenas de monumentos e sítios foram então identificados estando no prelo o trabalho que se lhes refere (V. Gonçalves et al., 1983). Tais prospecções integravam-se num projecto mais vasto de cartografia arqueológica do Algarve que tem vindo a funcionar no âmbito da Unidade de Arqueologia do Centro de Historia desde 1976.

O sítio da Lezíria foi então prospectado com especial interesse, consideradas anteriores informações e particularmente o achado de um ídolo calcolítico tipo Moncarapacho (V. Gonçalves, 1978). Compreende uma crista alongada de cota baixa (16 m), com um quilómetro de extensão, circundada por dois esteiros do Guadiana. Trabalhos agrícolas e a extracção de pedra puseram a descoberto abundante espólio arqueológico dos períodos romano e árabe.

O sítio da Lezíria situa-se a $875 \mathrm{~m}$ em linha recta do castelo de Castro Marim e enquadra-se numa região arqueológicamente rica sobretudo no que diz respeito aos períodos aí representados. Pertence à freguesia de Castro Marim, concelho de Castro Marim, distrito de Faro e define-se na quadrícula hectométrica (quadrícula militar portuguesa) pelas seguintes coordenadas de um seu ponto central: X-27.3; Y - 261.4. (C. M. P. 600). 
Foram recolhidos, sobretudo junto às valas das pedreiras, centenas de fragmentos cerâmicos atribuíveis ao período romano que compreendem para além de cerâmica comum, ânforas, "paredes finas» e terra sigillata. Do período árabe estava presente cerâmica vidrada melada e comum. Face ao seu elevado número, optámos por um estudo faseado, iniciado agora pela terra sigillata itálica e sudgálica.

\section{A «terra sigillata»}

São 102 os fragmentos de terra sigillata recolhidos na Lezíria e têm a seguinte distribuição: 24 de $t$. s. itálica, 38 de $t$. s. sudgálica, 47 de $t$. s. hispânica, 13 de $t$. s. clara (a, c e d). Serão objecto do presente estudo 12 fragmentos de $t$. $s$. itálica e 13 de $t$. s. sudgálica.

\subsection{A terra sigillata itálica}

É relativamente abundante a terra sigillata itálica no sítio da Lezíria. De 24 fragmentos apenas 10 permitiram uma reconstituição gráfica e 2 possuem marca de oleiro. Todos pertencem a formas lisas. Não é muito antiga, pertencendo a maioria aos períodos clássico e tardio e apenas um fragmento se integra no período precoce.

$\mathrm{O}$ n. ${ }^{\circ} 4$ da estampa II pertence à forma Goudineau 21, tipo 6 de Haltern, período precoce da produção itálica. Goudineau (Chr. Goudineau, 1968) considera que, apesar de o seu aparecimento poder colocar-se numa data relativamente alta (30-20 a.C.), a forma pode ter sobrevivido bastante tempo. Rara em Portugal, surge em Conímbriga em níveis superficiais (M. Delgado, et al., 1975) não contribuindo assim para um esclarecimento da sua cronologia.

$\mathrm{O}$ n. ${ }^{\circ} 1$ da estampa II pertence a um prato da forma Godineau 26 (serviço II tipo 2 de Haltern). $\mathrm{O}$ n. ${ }^{\circ} 5$ da mesma estampa poderá incluir-se na mesma forma, não sendo, no entanto, de excluir a hipótese de pertencer igualmente a um prato, mas da forma Goudineau 28 (serviço II tipo $3 \mathrm{~b}$ de Haltern). Os pratos 
da forma Goudineau 26, que fazem serviço com as taças da forma Goudineau 27, são muito raros em Oberaden, aparecendo em Haltern (S. Loeschcke, 1909) e Bolsena (Chr. Goudineau, 1968). Em Portugal são pouco frequentes. A forma 27 de Goudineau (serviço II tipo 8 de Haltern) é muito abundante nas estações portuguesas, nomeadamente em Miróbriga(L. Ferrer Dias, 1976-77), no castelo de Alcacer do Sal (L. Ferrer Dias, 1978) e em Conímbriga (M. Delgado et al., 1975) e está representada na Lezíria pelo fragmento ilustrado na estampa II n. ${ }^{\circ} 2$. A taça da forma Goudineau 27 e o prato da forma Goudineau 26, que com ele faz serviço, são muito frequentes em Haltern e muito raros em Oberaden, o que leva a concluir que a data do início do seu fabrico deve necessariamente colocar-se próximo do abandono do acampamento de Oberaden entre 10-9 a.C.

A forma Goudineau 28 (serviço II tipo 3b de Haltern), ilustrada pelo $\mathrm{n} .{ }^{\circ} 7 \mathrm{da}$ estampa II, tem como data provável do início do fabrico 1-3 d.G. e é pouco representada no material de Bolsena, aparecendo em maior número em Conímbriga. Registam-se também exemplares em Miróbriga.

A forma Goudineau 39, variante c, atribui-se ao n. 6 da estampa II, reservando-nos quanto à variante no que se refere ao n. $^{\circ} 8$ da mesma estampa. Evoluindo dos pratos da forma 26 de Goudineau, data-se o início do seu fabrico de 20-25 d.C. É abundante em Portugal, contando com vários exemplares em Conímbriga e no castelo de Alcácer do Sal.

Goudineau colocava a aparição da sua forma 43 entre 20-25 d.C. tendo sido entretanto esta data rectificada, com o seu aparecimento em Corinto, para 45 d.C. (J. W. Hayes, 1973). Está representada na Lezíria pelo $\mathrm{n} .{ }^{\circ} 3$ da estampa II. Está ausente de Haltern e Oberhausen e está bem representada em Conímbriga.

Também de produção tardia a forma 38 de Goudineau, variante a (tipo 12 serviço III), está presente na Lezíria (estampa III n. ${ }^{\circ}$ 1). Esta variante parece evoluir da forma 27 e faz o seu aparecimento antes de 16 d.C. É relativamente rara em Conímbriga. 


\section{CATÁLOGO}

ESTAMPA II

N. ${ }^{\circ} 1-72(82)$ Lez.

Fragmento de bordo e parede de catillus. Forma Goudineau 26; serviço II tipo 2 de Haltern. Bordo espesso e vertical bipartido na face interna e tripartido externamente. Face externa com ressalto diferenciando a zona superior convexa da inferior côncava. Ligação bordo parede marcada por um suave chanfro. Uma ranhura é ainda visível na zona convexa. $\mathrm{Na}$ face interna observam-se dois ressaltos, o primeiro imediatamente no início do bordo, o segundo limitando uma meia cana na ligação bordo parede. Pasta de cor laranja (2.5 YR 6/6), pouco dura com minúsculas partículas brancas e algumas bolhas de ar. Verniz de cor laranja escuro (2.5 YR 4/6), de espessura média, homogéneo e com brilho.

Diâmetro externo: $150 \mathrm{~mm}$.

N. ${ }^{\circ} 2-59(82)$ Lez.

Fragmento de bordo de taça. Forma Goudineau 27; serviço II tipo 8 de Haltern. Bordo vertical, bipartido externamente com forte proeminência na parte superior e rematado interiormente por cinco ranhuras e um ressalto. Face interna tripartida marcada por duas caneluras. Pasta de cor laranja (2.5 YR 4/6), de dureza média, bem depurada. Verniz de cor laranja (10 YR 4/6) de espessura fina, pouco homogéneo com manchas mais claras e com brilho.

Diâmetro externo: 139 mm.

N. ${ }^{\circ} .3-35(82)$ Lez.

Fragmento de bordo de prato um pouco mais pequeno que o catillus. Forma Goudineau 43. Bordo formado por um lábio arredondado e extrovertido e parede curvilínea. Pasta de cor laranja (2.5 YR 6/6), dura, bem depurada com minúsculas partículas brancas. Verniz laranja acastanhado (2.5 YR 5/6) de espessura média, homogéneo e com brilho.

Diâmetro externo: $127 \mathrm{~mm}$.

N.o $4-84(82)$ Lez.

Fragmento de pé e parede de taça. Forma Goudineau 21, tipo 6 de Haltern. Pé baixo e triangular, com linhas ligeiramente incurvadas, bem separado da parede por uma garganta. Parede interna oblíqua e curvilínea

Conimbriga, 24 (1985), 111-124 
marcada por um ressalto. Pasta de cor laranja claro (2.5 YR 6/4), pouco dura, facilmente riscada com a unha e bem depurada. Verniz de cor laranja (2.5 YR 4/6) de espessura fina, pouco homogéneo com manchas mais claras e com brilho. Na parede externa são visíveis marcas equidistantes do torno.

Diâmetro do pé: $50 \mathrm{~mm}$.

N. ${ }^{5}-77(82)$ Lez.

Fragmento de pé de prato. Forma provável Goudineau 26, serviço II tipo 2 de Haltern. Pé alto e pesado de secção rectangular, de paredes quase paralelas a tender para o vertical. Fundo plano e espesso ligeiramente alteado ao centro e decorado por um guilhoché muito fino. Pasta de cor ocre rosado (2.5 YR 6/4), pouco dura, facilmente riscada com a unha, depurada, com minúsculas partículas brancas. Verniz de cor castanha (2.5 YR 3/6), muito espesso, com tendência a estalar, com brilho.

Diâmetro do pé: $100 \mathrm{~mm}$.

N. ${ }^{\circ} 6-38(82)$ Lez.

Fragmento de bordo de catinus bessalis. Forma Goudineau 39, variante c. Bordo fino, ligeiramente oblíquo, rectilínio interior e exteriormente, limitado por dois bourrelets na face externa. A face interna apresenta um ressalto na zona superior. Pasta de cor beije (5 YR 7/4), pouco dura, facilmente riscada pela unha, muito bem depurada. Verniz de cor laranja (2.5 YR 5/8) de espessura muito fina, pouco homogéneo com manchas mais claras e com brilho.

Diâmetro externo: $181 \mathrm{~mm}$.

N. ${ }^{\circ} 7-85(82)$ Lez.

Fragmento de prato entre o catinus pedalis e o catinus palmipedalis. Forma Goudineau 28, serviço II tipo $3 \mathrm{~b}$ de Haltern. Bordo tripartido quase vertical. Na face externa, uma moldura limitada por dois ressaltos faz a ligação bordo parede. $\mathrm{Na}$ face interna, a parede é convexa e apresenta uma ranhura e uma canelura. Pasta cor de laranja (10 YR 5/6), bem depurada, dura e compacta. Verniz de cor laranja escuro (10 R 4/8), de espessura média, homogéneo e com brilho discreto.

Diâmetro externo: $320 \mathrm{~mm}$. 
N. ${ }^{\circ} 8-80(82)$ Lez.

Fragmento de parede de provável catinus pedalis. Forma Goudineau 39. Bordo rectilíneo limitado interiormente por um bourrelet. Pasta de cor ocre rosado (2.5 YR 6/4), dura, bem depurada com algumas minúsculas partículas brancas. Verniz de cor laranja (2.5 YR 4/8), de espessura fina, com manchas mais claras e com brilho.

\section{ESTAMPA III}

N. ${ }^{\circ} 1-76(82)$ Lez.

Fragmento de bordo e parede de taça. Forma Goudineau 38a, serviço III tipo 12 de Haltern. Bordo pouco espesso decorado por um guilhoché irregular. Moldura pendente e arredondada, decorada por um guilhoché descontínuo na parte superior. Lábio arredondado limitado na face interna por uma ranhura. Pasta de cor laranja (2.5 YR 5/6), dura, bem depurada, com partículas brancas e pouco compacta. Verniz de cor laranja escuro (10 R 4/6) de espessura média, pouco homogéneo, com um brilho muito discreto.

Diâmetro externo: $70 \mathrm{~mm}$.

\section{N. ${ }^{\circ} 2-74(82)$ Lez.}

Fragmento de pé. Forma indeterminada.

Pé alto, quase triangular com pequena superfície de apoio. Pasta de cor ocre rosado, pouco dura, facilmente riscada com a unha, bem depurada. Verniz de cor laranja (2.5 YR 4/8), de espessura fina, pouco homogéneo, com manchas mais claras e com brilho.

Diâmetro do pé: $80 \mathrm{~mm}$.

\subsection{As marcas de oleiro}

São apenas duas as marcas recolhidas sobre terra sigillata itálica. Ambas são centrais e de cartucho rectangular.

As marcas do oleiro CRESTUS, sendo frequentes em Portugal, raramente possuem o $\mathrm{S}$ retrógrado. Este facto regista-se apenas numa do Castelo das Guerras (J. O. Caeiro 1976-1977). No entanto, o ponto que separa o $\mathrm{R}$ do $\mathrm{E}$, visível na marca agora estudada, parece-nos inédito.

As marcas do oleiro STABILIS são, ao contrário, raras no território português. 


\section{CATÁLOGO}

ESTAMPA III

N. ${ }^{\circ} 3-65(82)$ Lez.

\section{CRESTUS ou CHRESTUS Oxé/Comfort 425}

Fragmento de um fundo horizontal de forma indeterminada. Caixilho sub-rectangular inserto num círculo. Marca em relevo CR.E2TL Apresenta a particularidade do $\mathrm{S}$ ser retrógrado e ter um ponto separando o $\mathrm{R}$ do $\mathrm{E}$. Pasta de cor ocre rosado (2.5 YR 6/4), de dureza média, bem depurada. Verniz de cor laranja (2.5 YR 4/8), de espessura fina, pouco homogéneo, com manchas mais claras e com brilho.

N. ${ }^{\circ} 4-50(82)$ Lez.

\section{STABILIS Oxé/Comfort 1848}

Fragmento de fundo de forma indeterminada, levemente côncavo e a diminuir de espessura para o centro. Caixilho incompleto de ângulos arredondados. Nâo é de excluir a hipótese de se tratar de uma marca in planta pedis. Marca em relevo ]BILI[. Pasta de cor rosa acastanhado claro (2.5 YR 5/4), pouco dura, compacta, com minúsculas partículas brancas e algumas bolhas de ar. Verniz de cor avinhada (2.5 YR 3/6), de espessura média, homogéneo e com brilho discreto.

\section{$2.2 \mathrm{~A}$ terra sigillata sudgálica}

De um total de 38 fragmentos de $t$. s. sudgálica, apenas 13 permitiram classificação e estudo, pertencendo 6 a vasos decorados e 7 a lisos.

Em relação aos primeiros integramos dois na forma Dragendorff 11 , um na 29, um na 37 e dois de difícil classificação que poderão incluir-se tanto na 29 como na 37.

Relativamente aos vasos lisos possuímos uma larga maioria de fragmentos incluídos na forma Dragendorff 18 (4), dois da forma 24/25 e um de difícil integração tipológica. 


\subsubsection{As formas decoradas}

Os vasos ruais antigos são os dois cálices da forma Dragendorff 11 ilustrados na estampa III, n. ${ }^{\text {os }} 6$ e 7, imitações de produtos itálicos e que datamos do reinado de Cláudio.

Quanto aos outros elementos decorados, sendo todos de dimensões muito reduzidas, sem perfis determinados e com motivos decorativos muito truncados, tornou-se muito difícil apontar uma cronologia precisa. Assim, podemos apenas situá-los entre os reinados de Cláudio e Vespasiano. O n. ${ }^{\circ} 10$ da estampa III, pela análise dos seus motivos decorativos, incluir-se-á no reinado de Vespasiano.

\subsubsection{As formas lisas}

As formas 24/25 e 18 são as mais representadas na Lezíria, aliás como acontece na maioria das estações portuguesas. Quanto à sua cronologia, ela corresponderá à das formas decoradas, entre Cláudio e Vespasiano, incidindo, aqui, a forma 18 no reinado deste último.

\section{CATÁlOGO}

ESTAMPA III

N. ${ }^{\circ} 7-89(82)$ Lez.

Fragmento de bordo e parede de cálice da forma Dragendorff 11. Bordo com lábio pendente com duas caneluras e uma moldura e decoração estriada; uma garganta profunda seguida de uma canelura e uma ranhura na face interna. Parede curvilínea em três movimentos destacada por duas molduras; a segunda, com estrias, marca o início da zona decorada da qual só é visível parte de uma linha dupla de óvulos. Pasta de cor laranja claro (2.5 YR 6/6), pouco dura, bem depurada, com algumas bolhas de ar. Verniz de cor laranja (2.5 YR 4/8), de espessura média, homogéneo e com brilho.

Diâmetro externo: $180 \mathrm{~mm}$. 
N.o $5-27(82)$ Lez.

Fragmento de parede de vaso decorado. Forma Dragendorff 29 ou 37. Parede espessa. Da decoração apenas conserva parte de uma grinalda de tipo reflectido médio decorrente com vestígios de parte de uma folha oval, sinuosa (Hermet, La Graufesenque, planche IX). Pasta de cor avermelhada (10 R 5/6) de dureza média, depurada, com minúsculas partículas brancas. Verniz de cor vermelha acastanhada (10 R 4/6), espesso, homogéneo e sem brilho.

N. ${ }^{\circ} 6-73(82)$ Lez.

Fragmento da parede de um vaso da forma Dragendorff 11. Parede fina, rectilínea e oblíqua. Linha de óvulos duplos separados por uma lingueta. Duas caneluras limitam superiormente o friso de óvulos. A parede interna é marcada por uma canelura larga e funda. Pasta de cor laranja claro (2.5 YR 6/6), bem depurada e mole. Verniz de cor laranja (2.5 YR 4/6), de dureza média com tendência a estalar, homogéneo e com brilho.

N.o $8-79(82)$ Lez.

Fragmento de parede de um vaso da forma Dragendorff 29. A parede é espessa, curvilínea e decorada por uma palissada de gomos limitada por duas linhas de pérolas. Pasta de cor vermelha acastanhada (2.5 YR 5/4), dura, bem depurada e com bolhas de ar. Verniz de cor castanha (10 R 4/8), espesso, homogéneo e com brilho.

N. ${ }^{\circ} 9-16(82)$ Lez.

Fragmento de parede de um vaso decorado. Forma Dragendorff 29 ou 37. Parede espessa. Da decoração conserva-se parte de uma grinalda de tipo reflectido médio decorrente com folha de difícil identificação, provavelmente cordiforme (Knorr, Tõpfer und Fabriken, fig. 9, Hermet, La Graufesenque, planche XL) e a parte posterior de uma ave. Esta decoração está enquadrada interiormente por uma canelura. Pasta de cor ocre rosado (2.5 YR 6/6), dura, depurada, compacta e com bolhas de ar. Verniz de cor avinhada (2.5 YR 3/6) de espessura média, homogéneo e de brilho discreto.

N. ${ }^{\circ} 10-47(82)$ Lez.

Fragmento de parede de um vaso decorado. Forma provável Dragendorff 37 . É decorado por uma grinalda com o ramo inferior ornamentado 
com um elemento vegetal trifoliado e com uma voluta. Esta grinalda é limitada por uma linha ondulada pertencente a uma métopa (Hermet, La Graufesenque, planche 80). Pasta de cor avermelhada (10 R 5/6), de dureza média, porosa, depurada, com minúsculas partículas brancas. Verniz de cor laranja acastanhado (10 R 4/6), espesso, homogéneo e com brilho.

N. ${ }^{\circ} 11-91(82)$ Lez.

Fragmento de taça da forma Dragendorff 24/25. Bordo vertical, arredondado superiormente e decorado por um guilhoché muito fino, seguido de uma moldura saliente. $\mathrm{Na}$ parede interna é visível uma canelura. Pasta bem depurada de cor laranja (10 $\mathrm{R} 5 / 6)$, dura, com minúsculas partículas brancas e algumas bolhas de ar. Verniz de cor amarelada (7.5 YR 6/6), raiado a vermelho (10 $\mathrm{R} \mathrm{4/8),} \mathrm{homogéneo,} \mathrm{espesso} \mathrm{e} \mathrm{sem} \mathrm{brilho.}$

Diâmetro externo: $129 \mathrm{~mm}$.

N. ${ }^{\circ} 12-42(82)$ Lez.

Fragmento de parede de taça de forma Dragendorff 24/25. É decorado por um guilhoché irregular delimitado superiormente por duas caneluras. Pasta de cor laranja (2.5 YR 6/6), de dureza média, bem depurada, com minúsculas partículas brancas e porosa. Verniz de cor acastanhada (10 R 4/8), pouco espesso, homogéneo e sem brilho.

\section{ESTAMPA IV}

N. ${ }^{\circ} 1-75(82)$ Lez.

Fragmento de catinus palmipedalis. Forma Dragendorff 18. Bordo fino, curto e aberto com um pequeno lábio arredondado. Na face interna observam-se três ranhuras. Pasta de cor laranja acastanhada (2.5 YR 5/6), dura, depurada, com minúsculas partículas brancas e algumas bolhas de ar. Verniz laranja (10 R 4/8), de espessura média, homogéneo e com brilho.

Diâmetro externo: $342 \mathrm{~mm}$.

$\mathrm{N}^{0} 2-66(82)$ Lez.

Fragmento de catinus bessalis. Forma Dragendorff 18. Bordo fino, curto e aberto com um pequeno lábio arredondado. Pasta de cor laranja claro (2.5 YR 6/6), dura, depurada, com minúsculas partículas brancas. Verniz de cor laranja (10 R 4/8), de espessura média, homogéneo e com brilho.

Diâmetro externo: $180 \mathrm{~mm}$. 
N $03-86(82)$ Lez.

Fragmento de pé de prato muito provavelmente da forma Dragendorff 18. Pé alto, com exterior anguloso e superfície de apoio reduzida. Um ressalto marca a ligação interna do pé com o fundo. Fundo pouco espesso, quase horizontal, com um sulco escavado. Ressalto interior. Pasta vermelha acastanhada (2.5 YR 5/4), dura, depurada, com minúsculas partículas brancas e algumas bolhas de ar. Verniz de cor laranja escuro acastanhado (10 R 4/6), espesso, com tendência para estalar, homogéneo e com brilho.

Diâmetro do pé: $85 \mathrm{~mm}$.

N o $4-87(82)$ Lez.

Fragmento de pé de prato da forma Dragendorff 18. Pé alto, com exterior anguloso e superfície de apoio reduzida. Um ressalto marca a junção interna com o fundo. Exteriormente é visível uma canelura. Fundo pouco espesso, largo, subindo para o centro, escavado por um sulco. Ressalto interior. Pasta de cor laranja acastanhado (10 R 5/6), dura, depurada, porosa, com minúsculas partículas brancas. Verniz de cor laranja escuro acastanhado (10 R 4/6), de espessura média com tendência para estalar.

Diâmetro do pé: $90 \mathrm{~mm}$.

N. ${ }^{\circ} 5-81(82)$ Lez.

Fragmento de um pé de um prato de ferma indeterminada. Pé alto com exterior anguloso e superfície de apoio média. Internamente são visíveis duas ranhuras. Fundo pouco espesso, escavado por um sulco. Pasta de cor laranja acastanhado (10 R 4/6), dura, depurada, com minúsculas partículas brancas. Verniz de cor castanho avermelhado (10 R 4/6), de espessura média, pouco homogéneo e com pouco brilho.

Diâmetro do pé: $86 \mathrm{~mm}$. 


\section{BIBLIOGRAFIA}

CAE I ro, J. O. (1976-1977), Marcas de oleiro em terra sigilatta itálica do Castelo das Guerras [Moura), «Setúbal Arqueológica», II-III, pp. 419-422.

Delgado, M., Mayet, F., Alarcão, A. M. (1975), Les sigillées, Fouilles de Conimbriga, IV, Paris.

Ferrer Dias, L. (1976-1977), Terra sigillata de Miróbriga, «Setúbal Arqueológica», II-III, pp. 361-418.

FerRer Dias, L. (1978), As marcas de terra sigillata do castelo de Alcácer do Sal, «Setúbal Arqueológica», IV, pp. 145-154.

Gonçalves, V. (1978). Dois novos idolos tipo Moncarapacho, «Setúbal Arqueológica», IV, pp. 47-58.

Gonçalves, V., arruda, A. M., Carvalho dias, A., Catarino, H., Oliveira, J., (1983), A Carta Arqueológica do Algarve, 1. A C. M. P. 591 - Inventário de monumentos e sítios, «Glio Arqueologia», 1 (no prelo).

Goudineau， Chr. (1968), La céramique aretine lisse, Fouilles de Bolsena IV, Paris.

Hayes, J. W. (1973), Roman Pottery from de south stoa at Corinth, «Hesperia» XLII, pp. 416-470.

Hermet, F. (1934), La Graufesenque (Condatomago), Paris.

KNORR, R. (1919), Tópfer und Fabriken Verzierter Terra Sigillata des ersten Jahrhunderts, Stuttgart.

LOESCHCKe, S. (1909), Keramische Funde in Haltern: ein Beitrag zur Geschichte der augusteichen Kultur in Deutschland (Mitteilungen der Altertumskommission fiir Westfalen, 5), Bona.

OxÉ, A., Cомғо т т, H. (1968), Corpus vasorum arretinorum, Bona. 
EsT. I
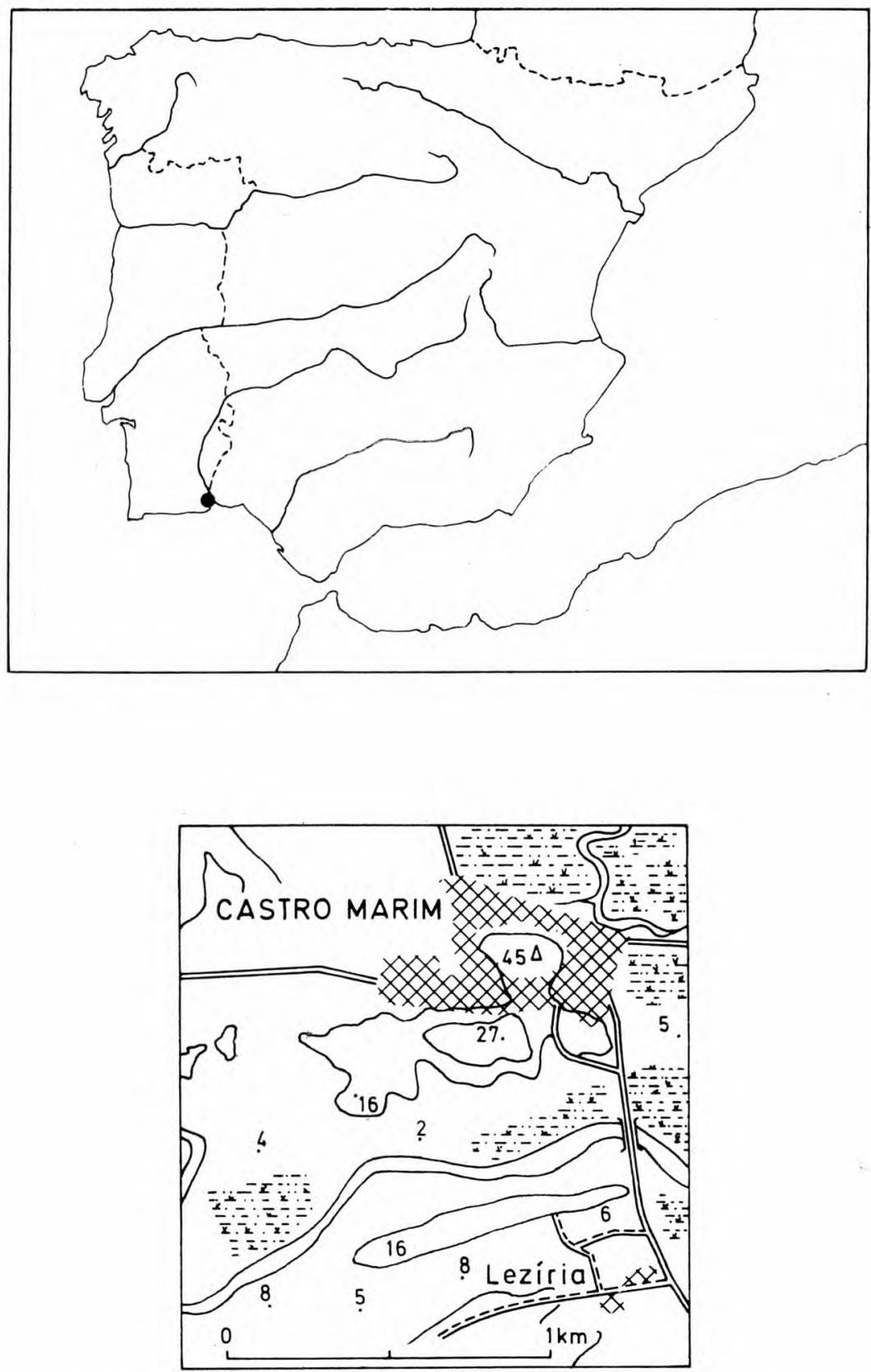

Lccalização do sítio da Leziria na Península Ibérica e na carta 1:25 000 
Est. II

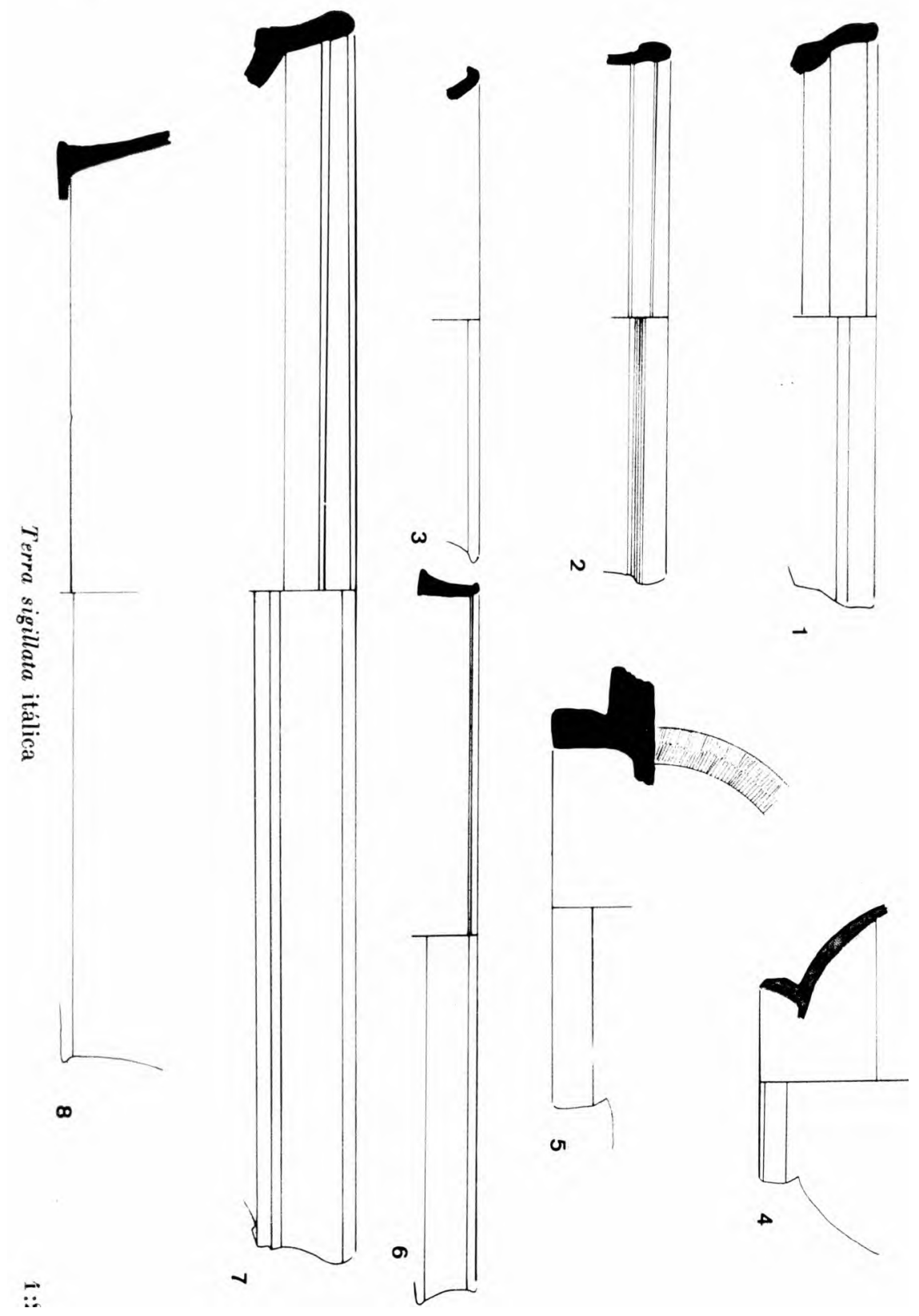


Est. III
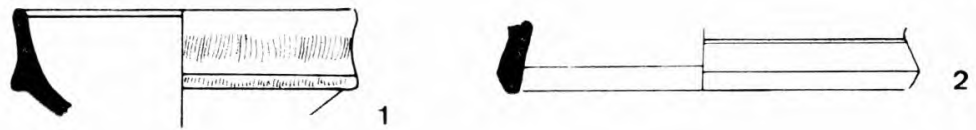

CREETI 3

IILO 4

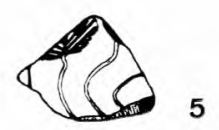

5
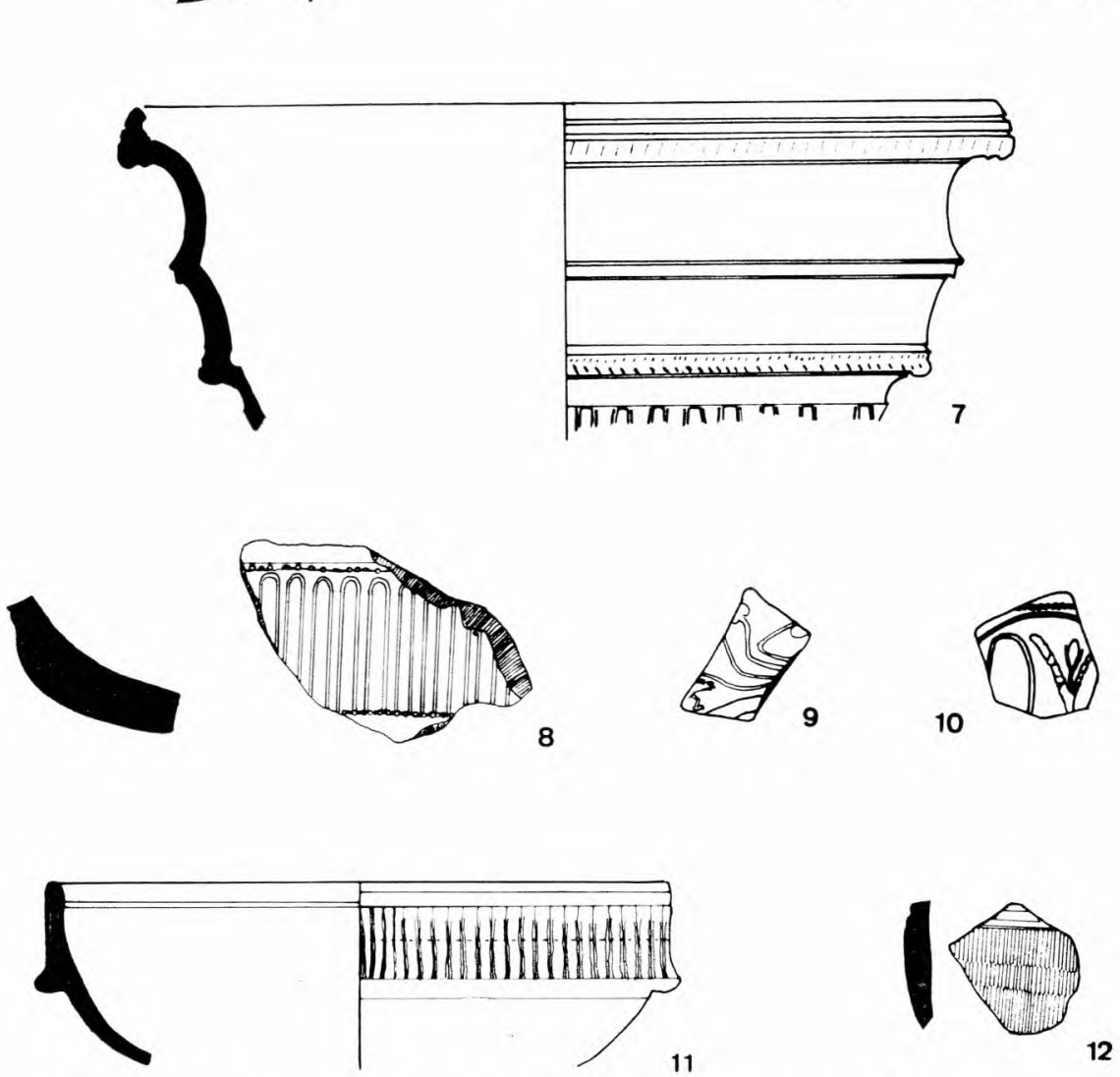

Terra sigillata itálica (1-4). Terra sigillata sudgálica (5-12). 
EsT. IV
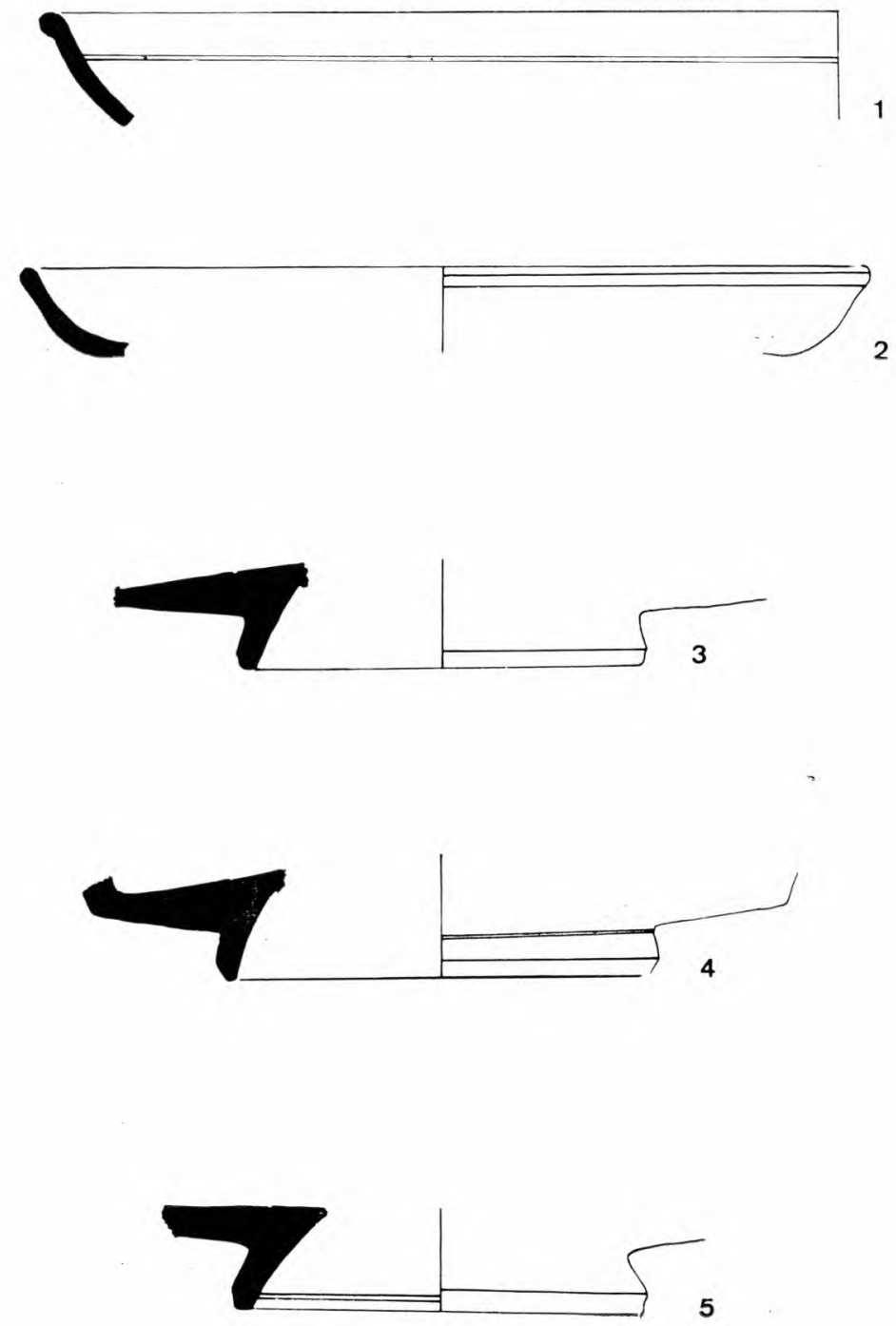

Terra sigillata sudgálica. 